\title{
TAPPING THE VALUE POTENTIAL OF EXTENDED ASSET SERVICES - EXPERIENCES FROM FINNISH COMPANIES
}

\author{
Helena KORTELAINEN, Jyri HANSKI, Pasi VALKOKARI, Toni AHONEN \\ VTT Technical Research Centre of Finland
}

\begin{abstract}
:
Recent developments in information technology and business models enable a wide variety of new services for companies looking for growth in services. Currently, manufacturing companies have been actively developing and providing novel asset based services such as condition monitoring and remote control. However, there is still untapped potential in extending the service delivery to the long-term co-operative development of physical assets over the whole lifecycle. Close collaboration with the end-customer and other stakeholders is needed in order to understand the value generation options. In this paper, we assess some of the asset services manufacturing companies are currently developing. The descriptions of the asset services are based on the results of an industrial workshop in which the companies presented their service development plans. The service propositions are compared with the Total Cost of Ownership and the closed loop life cycle frameworks. Based on the comparison, gaps that indicate potential for extended asset service concepts are recognised. In conclusion, we argue that the manufacturing companies do not recognise the whole potential for asset based services and for optimizing the performance of the end customers' processes.
\end{abstract}

Key words: asset, fleet, extended asset services

\section{INTRODUCTION}

Companies operating in the manufacturing sector typically have a large quantity of different physical assets, such as machinery, equipment and infrastructure. These assets are managed in order to achieve the best possible short and long-term asset performance. The modern industrial environment involves a number of organizations as key stakeholders including asset operators and owners, regulatory and statutory bodies, service providers, engineering contractors, technology developers, equipment manufacturers, spare part vendors and logistic providers [1]. The asset performance can be assessed with direct, indirect, financial and non-financial measures, and from the economic, social and environmental perspectives [2]. Because of the multiple performance dimensions and stakeholders involved, the assessment and the improvement of the asset performance are complex tasks.

Manufacturing assets typically have long life cycles and major changes may occur in all the external and internal factors on which the investment calculations have been originally based [3]. Eventhough it is a well-known fact that the major part of the costs incur over the life-cycle, the acquisition price drives decisions in the investment phase $[4,5]$. The companies make efforts to maximise asset productivity. Asset management calls for approaches where localised resources and capabilities are blended together with external resources and capabilities [1]. In order to stay competitive, manufacturing companies need to better utilise the data from their supply chain, stakeholders and other external sources. An active engaging of network partners will be needed for innovations to occur [6] since a wide collaboration assures that experiences, know-how and knowledge of various stakeholders can be used and combined [7]. Combining knowledge allows collaborating parties to achieve levels of knowledge and to create outcomes, which individual by themselves are not capable of [8].

Implementation of loT platforms is expected to result in a series of benefits for manufacturing operations and asset management, for instance, increasing visibility of the manufacturing operations and across the supply chain, improved efficiencies, automation of workflow, optimized energy consumption, improved preventive maintenance, and realtime information exchange among manufacturing facilities and across supply chain [9]. Physically distributed resources and abilities controlled by different parties are made available to the companies that need those resources through a cloud service $[10,11]$. In addition, companies may have an access to data from the installed base of machines and infrastructure located anywhere [12]. This data may be used for assessing the performance of a single machine compared to the current and previous performance of the entire fleet [13].

Currently, manufacturing companies have been actively developing and providing asset services such as condition monitoring and remote control that help to improve asset performance. In our opinion, there is still untapped potential in extending the service delivery to the long-term cooperative development of physical assets over the whole lifecycle in close collaboration with the end-customer and other stakeholders. The goal of this paper is to identify the 
opportunities for extending the service offering beyond the current delivery.

In this paper, we assess some of the asset services that the manufacturing companies are currently developing. The paper is collected in an ongoing Finnish nationally funded research project "S4Fleet - Service solutions for Fleet management". The descriptions of the asset services are based on the results of a company workshop, where the companies presented their service development plans. The services are compared with the total cost of ownership and a closed-loop life cycle frameworks. Based on the comparison, gaps for potential extended asset service concepts are recognised.

\section{EXTENDED ASSET SERVICES}

In this chapter, the most crucial terms for this study are defined. Firstly, the terms asset and asset management are defined based on ISO 55000 [2].

Asset is "an item, thing or entity that has potential or actual value to an organization. The value will vary between different organizations and their stakeholders, and can be tangible or intangible, financial or non-financial".

Asset management "involves the balancing of costs, opportunities and risks against the desired performance of assets, to achieve the organizational objectives. It enables an organization to examine the need for, and performance of, assets and asset systems at different levels. Additionally, it enables the application of analytical approaches towards managing an asset over the different stages of its life cycle".

To support the asset management, services can be provided by several agents such as the owner of the asset, the provider of the asset, a service provider or another stakeholder. When a service is fully or partially based on the data that originates from assets, or it supports the operation and/or the development of the assets, these services are defined as asset services in the context of this study. Asset services can be, for instance, remote control, condition monitoring or product use based services.
According to ISO 55000 [2] assets should be managed during their whole life cycle with analytical approaches using multiple decision criteria and objectives. Additionally, asset management is executed at different organisational and system levels. In order to answer these requirements, companies delivering asset services need to establish longterm customer relationships and understand the whole life cycle of the managed assets from the perspective of all the relevant actors and stakeholders. In this study, we call the services needed to fulfil these requirements extended asset services.

\section{METHODOLOGY}

The empirical research was carried out in co-operation between researchers and companies. During our research, industrial companies were asked to present their development goals and plans related to data-based industrial services in a structured workshop. The industrial participants are experts from different branches and they represented technology, service and IT providers, and software companies. The participating companies are listed in Table 1. During the workshop the researchers analysed the presentations and collected the data dealing with the service concepts and their expected benefits to the potential customers. Especially, the descriptions and prospects of the asset management related services were recorded.

\section{Total cost of ownership model}

Services that the companies described during the workshop are assessed against two frameworks: the Total Cost of Ownership (TCO) and closed loop life cycle framework. The selected frameworks represent important future development pathways for extending asset services; monetizing the benefits and costs, and enhancing the sustainability and circular economy practices of asset management services. In our analysis we aim to identify which framework phases or areas are addressed by services and which phases or areas offer space for extended asset services.

According to Ellram [14] Total Cost of Ownership (TCO) is a purchasing tool and philosophy which is aimed at un-

Table 1

Industrial partners participating in the study

\begin{tabular}{cccc}
\hline $\begin{array}{c}\text { Company } \\
\text { Identifier }\end{array}$ & Company description & Role in the loT ecosystem & Company size \\
\hline A & Equipment and service provider & Asset service & Large \\
B & Equipment and service provider & Asset service & Large \\
C & Technology and service provider & Large \\
D & Equipment and service provider & Asset service & Large \\
E & Technology and service provider & Asset service & Large \\
F & Information service provider & Asset service & SME \\
G & $\begin{array}{r}\text { Information service } \\
\text { and infrastructure provider } \\
\text { Information service } \\
\text { and infrastructure provider } \\
\text { Information service } \\
\text { and infrastructure provider } \\
\text { Information service provider }\end{array}$ & Asset service enabler & Asset service enabler \\
I & Information service \\
and infrastructure provider & Asset service enabler & Medium \\
K & Asset service & Asset service enabler & SME \\
\hline
\end{tabular}


derstanding the true cost of buying a particular good or service form particular supplier. In addition to the acquisition price, TCO may include such elements as transportation, inspection, replacement, downtime caused by failure, disposal costs and so on. A standard model for TCO calculation hardly exists [14, 15] but some cost drivers are more universal than others and will appear in many TCO valuation models. As our case companies provide investment goods and related services we choose a TCO-model developed by Keys and Chen [5] for heavy equipment. Fig. 1 contemplates the breakdown of the Total Cost of Ownership (TCO) during the life cycle of a product or service. Additionally, it points out the potential asset management value creation options.
The economic perspective as described in TCO framework is, however, not sufficient to describe the performance of asset management. Asset management should be a key driver for improving the sustainability of companies [17]. Taking the social and environmental perspectives into account in addition to the economic perspective gives a more complete view on asset management.

\section{Closed loop life cycle framework}

In comparison to the TCO framework, the closed loop life cycle framework (Fig. 2) represents a circular model of a life cycle where technical and biological resources such as products, machinery, equipment, material and energy are returned to the cycle after their first life cycle.

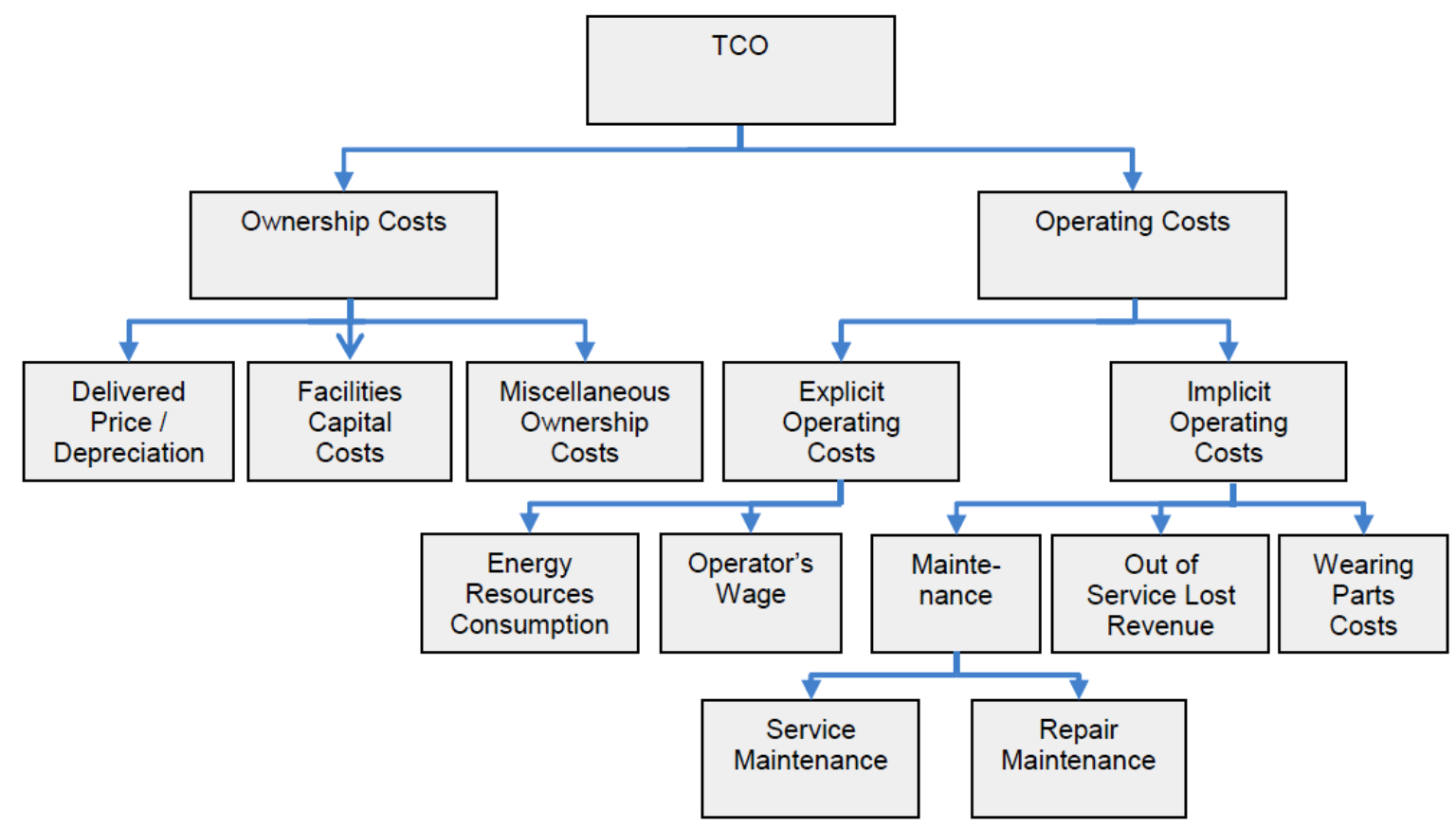

Fig. 1 Total cost of ownership framework according to Keys and Chen Source: [5].

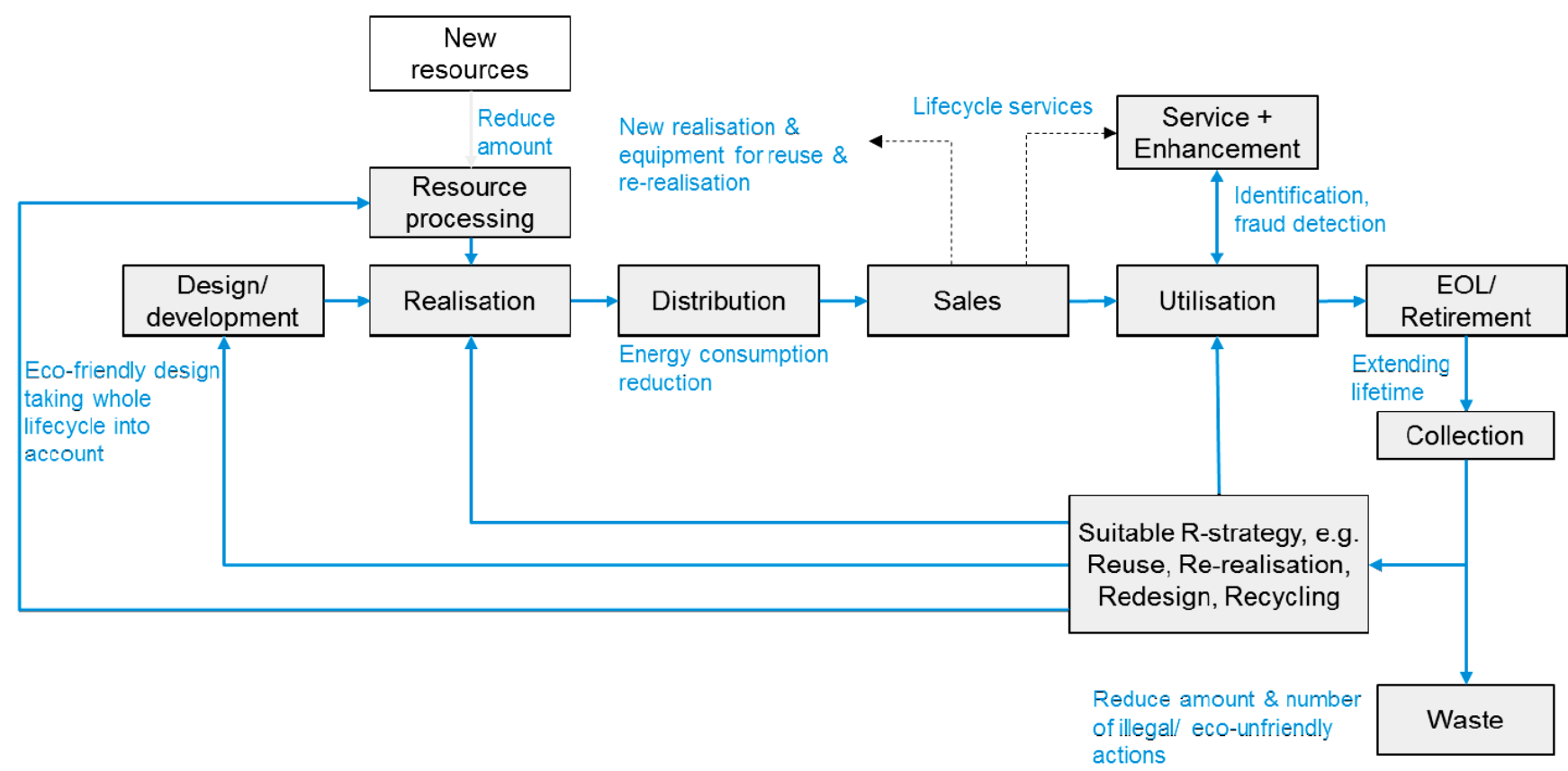


Circular economy is "restorative and regenerative by design, and aims to keep products, components, and materials at their highest utility and value at all times" [18]. The closed loop life cycle supports sustainable product and service development. It complements the traditional life cycle models by including the material and information flows related to the manufacturing, realisation, distribution, utilisation and end-of-life of a product or service.

The closed loop life cycle contains several feedback loops which enable new kinds of asset based services. These asset based services are enabled by the development of the Internet of things technologies that makes it possible to keep track of the valuable smart products, services and material much more economically than earlier [16]. The development of ICT has brought forth opportunities especially for implementing new R-strategies and waste management practices [16].

\section{RESULTS}

\section{Service Concepts}

Table 2 describes shortly the service concepts as expressed by the case companies. The service concepts in the case companies are classified into two groups - the asset based services and the ICT services enabling them.

Table 2

Description of the developed service concepts

\begin{tabular}{ll}
\hline Service type & Service concept \\
\hline $\begin{array}{l}\text { Asset } \\
\text { service (A) }\end{array}$ & $\begin{array}{l}\text { Service for analysis of maintenance, failures and life- } \\
\text { times }\end{array}$ \\
Asset & $\begin{array}{l}\text { Services for predicting equipment failures, predictions } \\
\text { for unit's performance, maintenance and defining } \\
\text { bervice (B) }\end{array}$ \\
$\begin{array}{l}\text { Asset } \\
\text { service (C) }\end{array}$ & $\begin{array}{l}\text { Service for optimizing operations and maintenance } \\
\text { activities, and estimating total life cycle costs. }\end{array}$
\end{tabular}

Asset

service (D)

Asset

service $(E)$

Asset

service $(F)$

Asset

service enabler (G)

Asset

service enabler $(\mathrm{H})$

Asset

service enabler (I)

Asset

service (J)

Asset

service enabler (K)
Analytics and platform for predictive maintenance and asset optimization solutions for fleet management

Services for predictable and guaranteed failure free run to the customer based on using machinery and equipment related data.

Logistics services and material stream analyses for improved logistic processes.

Service manager view to integrated fleet level and customer profiling information

Platform and technical means for loT solutions

Offering collaboration platforms which combine data from different sources

Helping customers to focus development efforts to improve OEE. Using software and working practice to manage reliability and RAMS requirements.

Platform/infrastructure service for extending the existing service from measuring the asset level to the fleet-level.
Service concept details

to identify the possible over or under maintenance, to improve maintenance effectiveness, lifetime of products, subsystems and components, and failure probability estimates

to predict equipment failures and unit's performance and to define best practice by combining data

the optimization of operations using multiple data sources and advanced data analysis, defining best maintenance practices through benchmarking different customer segments.

to improve the maintenance services, the understanding of the production environment and its causes and effects, and the capabilities for selecting correct maintenance options.

to complement the own data by external data from the customers.

to improve logistics services and material stream analyses, and providing a plan for every part in the supply chain.

utilise new opportunities for comparing and analysing logistics processes.

to make important information available to field service personnel and maintenance management to support their decision-making.

IoT solutions that increase production output, eliminate breakdowns, predictive maintenance modelling, reduction in downtime, maintenance and service costs, optimizing logistics services, enabling new services

to support predictive maintenance, asset optimization and advanced analytics in customer companies to, for instance, reduce costs and optimise operations

predictive maintenance and asset optimization solutions for fleet management.

big data analytics

to combine maintenance information from various systems, improving the validity services for ensuring data quality in the customers' information systems.

to support design for reliability, risk assessment, maintenance optimization decisions and maintenance planning decisions

to provide remote monitoring and asset control for supporting asset management decisions and benchmarking.

Predictability information of fleet (e.g. KPIs) 
These categories are rough but the classification helps to understand the role of the company in the service ecosystem.

\section{Assessment of the service concepts}

Table 3 presents the life cycle cost elements in the TCO and the phases in the closed loop life cycle framework. The described elements/phases have been used for the analysis of the service offering summarized in Table 2.

Table 3

The phases in the tco and the closed loop life cycle frameworks

\begin{tabular}{ll}
\hline TCO framework cost elements & $\begin{array}{l}\text { Phases in the closed loop } \\
\text { life cycle framework }\end{array}$ \\
\hline $\begin{array}{l}\text { 1. Ownership costs: } \\
\text { a. delivered price, }\end{array}$ & 1. Design and development \\
$\begin{array}{l}\text { b. facilities capital costs, } \\
\text { c. miscellaneous ownership }\end{array}$ & $\begin{array}{l}\text { 2. Realisation: } \\
\text { a. resource processing, } \\
\text { b. new resources, } \\
\text { 3. Distribution }\end{array}$ \\
& 4. Sales \\
$\begin{array}{ll}\text { 2. Explicit operating costs: } & \text { 5. Utilisation } \\
\text { a. energy, } & \text { a. service + enhancement } \\
\text { b. operator's wages. } & \\
\text { 3. Implicit operating costs: } & \\
\text { a. maintenance - service, } & \\
\text { b. maintenance - repair, } & \\
\text { c. out of service lost revenue, } & \\
\text { d. wearing parts cost. } & \text { 6. End-of-Life or retirement: } \\
& \text { a. collection, } \\
& \text { b. suitable R-strategy, }\end{array}$ \\
\hline
\end{tabular}

Table 4 visualises in which phases of the TCO model and the closed loop framework the service concepts of the case companies provide support. Additionally, the goal of the analysis is to highlight the potential for completely new services. The evaluation is based on the expert opinion of the authors.

Table 4

Comparing the service conceps with the TCO-model and the sustainability framework

\begin{tabular}{ccc}
\hline Company & $\begin{array}{c}\text { TCO } \\
\text { framework }\end{array}$ & $\begin{array}{c}\text { Closed loop life } \\
\text { cycle framework }\end{array}$ \\
\hline Asset based services (A) & $3 a, b$ & 5 \\
Asset based services (B) & $3 a, b$ & 5 \\
Asset based services (C) & $1-3$ & All phases \\
Asset based services (D) & $3 a, b$ & 5 \\
Asset based services (E) & - & $2-5$ \\
Asset based services (F) & $3 a, b$ & $3-5$ \\
Asset service enabler (G) & 2,3 & $2-6$ \\
Asset service enabler (H) & 2,3 & $5(-6)$ \\
Asset service enabler (I) & $3 a, b$ & 5 \\
Asset based services (J) & $1 a, 3$ & 1,5 \\
Asset service enabler (K) & $3 b$ & 5 \\
\hline
\end{tabular}

The companies offering asset based services seem to concentrate their offering development especially to maintenance services with the aim to improve the predictability and efficiency of maintenance actions. Only one pro- vider (Company C) expressed the intention to extend the offering towards full life cycle services. The closed-loop framework yields the same finding: the service focus is in the utilisation phase. None of the asset service providers mentioned wearing parts. The applied TCO model was coarse and for this reason the services delivered by the logistics company (Company E) could not be classified.

One software company (Company J) offered services for design and development and utilisation phases that correspond the ownership costs and implicit operating costs in the TCO-model. The companies offering enabling technologies (Companies $\mathrm{G}, \mathrm{H}, \mathrm{I}$ and $\mathrm{J}$ ) focus also in supporting the utilisation phase and corresponding cost elements in their development work. However, the offered technologies may have much broader application area.

The analysis seems to confirm the assumptions that the manufacturing companies concentrate their service offering development to the utilisation phase asset performance with the emphasis on reducing maintenance costs. This endeavour is supported by enabling ICT technologies (asset service enablers). Less activities are addressing the ownership costs and explicit operating costs, or to the emerging service options in the end-of-life management. A lot of feedback loops in the closed loop model are not covered by the services such as those connected to design and development, realisation and end-of-life or retirement. There is a lot of untapped service potential and extending the service delivery beyond current asset services may help the companies to answer to the recognised service needs.

\section{CONCLUSIONS}

Manufacturing companies have been actively developing and providing asset based services such as condition monitoring and remote control that help to improve asset performance at the customer's production sites. IoT platforms are important enablers that are needed to offer novel services also to distributed asset fleets and to ensure real-time information exchange across the supply chain. However, close collaboration with the end-customer and other stakeholders is needed to understand the everchanging customer needs, business and operation environment, and value generation options.

In this study, we used two general frameworks to illustrate customer needs, namely the Total Cost of Ownership (TCO) model and a closed loop life cycle framework. Selected frameworks represent important future development pathways for extending current asset services; monetizing the benefits and costs, and enhancing the sustainability and circular economy practices of asset management services. Thus, the models and frameworks help the technology and service providers to better understand what actions, task and processes the customers carry out, and what cost and value elements drive their actions.

The analysed descriptions for the development of asset based services and the ICT services enabling them seem to confirm the assumptions that the manufacturing companies concentrate their service offering development to the utilisation phase asset performance with the emphasis on reducing maintenance costs. When comparing the service delivery with the TCO model and closed loop life cycle framework it revealed gaps in their service offering. It seems that service providers have not yet recognized the whole growth potential when designing new services as they stick mainly on the data that originates from assets and aim to supports the operation and/or maintenance of 
the assets rather than co-developing the process with the customer or other stakeholders. Based on the analysed material, extended asset service concepts currently do not exist, however, they are made possible by the asset service enablers.

The service offering gaps indicate potential for extending the service delivery and creating new service concepts together with the customers. Manufacturing companies seem not to recognise the whole potential for asset based services and optimizing the performance of the end customers' processes. In our study, extended asset services refer to the extension of the service delivery to the longterm co-operative development of physical assets over the whole lifecycle. Close collaboration with the end-customer and other stakeholders is needed in order to understand the value generation options of the extended asset services. There is a lot of untapped service potential and extending the service delivery beyond current asset services may help the companies to answer to the recognised service needs.

This study focused on seven asset services and four services that enable asset services to be provided. Larger amount of service concepts should be analysed to provide more accurate insights about the asset services and service development in companies, and the usefulness of the proposed assessment approach.

\section{ACKNOWLEDGMENT}

The authors gratefully acknowledge DIMECC (Digital, Internet, Materials \& Engineering Co-Creation) for organizing Service Solutions for Fleet Management program (S4Fleet), the Finnish Funding Agency for Technology and Innovation (Tekes) for funding the program and the companies involved in the research.

\section{REFERENCES}

[1] J.P. Liyanage, "Smart Engineering Assets through Strategic Integration: Seeing Beyond the Convention," in Asset Management: The State of the Art in Europe from a Life Cycle Perspective, T. van der Lei, P. Herder and Y. Wijnia, Dordrecht: Springer Netherlands, 2012, pp. 11-28.

[2] ISO 55000:2014 Asset management - Overview, principles and terminology, International Organization for Standardization, 2014.

[3] K. Komonen, H. Kortelainen and M. Räikkönen, "Corporate Asset Management for Industrial Companies: An Integrated Business-Driven Approach", in Asset Management: The State of the Art in Europe from a Life Cycle Perspective, T. van der Lei, P. Herder and Y. Wijnia, Dordrecht: Springer Netherlands, 2012, pp. 47-63.

[4] B.S. Blanchard and W.J. Fabrycky, Systems engineering and analysis, 3rd edition, Eaglewood Cliffs (NJ): Pretice Hall, 2000.

[5] L. Keys and S. Chen, "A cost analysis model for heavy equipment", Computers \& Industrial Engineering, vol. 56, no. 4, pp. 1276-1288, 2009.
[6] I. Miles, "Service innovation: coming to age in the knowledge-based economy", International Journal of Innovation Management, vol. 4, no. 4, pp. 371-389, 2000,

[7] T. Ahonen, M. Reunanen, O. Pajari, V. Ojanen and M. Lanne, "Maintenance communities - A new model for the networked delivery of maintenance services", International Journal of Business Innovation and Research, vol. 4, no. 6, pp. 560-583, 2010.

[8] L. Wiseman and G. McKeown, "Managing Yourself: Bringing out the best in your people", Harvard Business Review, vol. 88, no. 5, pp. 117-121, 2010.

[9] R.F. Babiceanu and R. Seker, "Big Data and virtualization for manufacturing cyber-physical systems: A survey of the current status and future outlook", Computers in Industry, vol. 81, pp. 128-137, 2016.

[10] B. Esmaeilian, S. Behdad and B. Wang, "The evolution and future of manufacturing: A review", Journal of Manufacturing Systems, vol. 39, pp. 79-100, 2016.

[11] F. Tao, L. Zhang, V.C. Venkatesh, Y. Luo and Y. Cheng, "Cloud manufacturing: a computing and serviceoriented manufacturing model", Journal of Engineering Manufacturer, vol. 225, no. 10, pp. 1969-1976, 2011.

[12] J. Hanski, H. Kortelainen and T. Uusitalo, "The impact of digitalization on product-service system development in the manufacturing industry - an interview study", Manuscript sent to International Journal of Services Technology and Management, 2016.

[13] J. Lee, B. Bagheri and H-A. Kao, "A Cyber-Physical Systems architecture for Industry 4.0-based manufacturing systems", Manufacturing Letters, vol. 3, pp. 18-23, 2015.

[14] L. Ellram, "Total Cost of Ownership. An analysis approach for purchasing", International Journal of Physical Distribution \& Logistics Management, vol. 25, no. 8, pp. 4-23, 1995.

[15] B. Ferrin and R. Plank, "Total Cost of Ownership Models: An Explaratory Study", Journal of Supply Chain Management, vol. 38, no. 2, pp. 18-29, 2002.

[16] P. Valkokari, N. Tura, M. Martinsuo, K. Dooley, J. Hanski, J. Jännes, J. Kivilä, K. Palomäki, M. Reunanen, I. Sukanen and K. Valkokari (2016, May 23). Sustainable business - Case studies from Finnish forerunners [Online]. Avilccable: http://www.vtt.fi/inf/julkaisut/ muut/2016/Sustainable_business_case\%20studies\% 20from\%2 OFinnish\%20forerunners.pdf

[17] D.R. Marlow, "Sustainability-Based Asset Management in the Water Sector", in Definitions, Concepts and Scope of Engineering Asset Management, series Engineering Asset Management Review, vol. 1, J.E. Amadi-Echendu, K. Brown, R. Willett and J. Mathew, Eds. London: Springer-Verlag London, 2010, pp. 261275.

[18] Website of Ellen MacArthur Foundation. (2016, August 30). Circular Economy Overview [Online]. Available: http://www.ellenmacarthurfoundation.org/ circular-economy/overview/concept 